\title{
Finite Element Analysis of Maximum Electric Field for Air Breakdown Under Various Electrode Configurations
}

\author{
Nur Farhani Ambo', Hidayat Zainuddin*2, Muhammad Saufi Kamarudin³, Jamaludin Mohd Wari", \\ Ayuamira Zahari $^{5}$ \\ ${ }^{1,2,5} \mathrm{High}$ Voltage Engineering Research Laboratory, Faculty of Electrical Engineering, \\ Universiti Teknikal Malaysia Melaka, Malaysia \\ ${ }^{3}$ Faculty of Electrical and Electronic Engineering, Universiti Tun Hussein Onn, Malaysia \\ ${ }^{4}$ Indkom Engineering Sdn. Bhd., Malaysia
}

\begin{tabular}{|c|c|}
\hline Article Info & ABSTRACT \\
\hline Article history: & This paper describes the electric field behavior of air breakdown under \\
\hline Received Dec 12, 2018 & various electrode configurations and gap length. By using COMSOL \\
\hline Revised Feb 1, 2018 & maximum electric field can be determined based on the air breakdown \\
\hline Accepted Feb 21, 2018 & $\begin{array}{l}\text { voltage data obtained from the experiment under AC stress. The results show } \\
\text { that R0.5-plane configuration provides a very high electric field upon }\end{array}$ \\
\hline Keywords: & $\begin{array}{l}\text { breakdown, compared to R6-plane, R48-plane and plane-plane } \\
\text { configurations. In addition, the comparison between the analytical and }\end{array}$ \\
\hline $\begin{array}{l}\text { Air breakdown } \\
\text { Air insulation }\end{array}$ & $\begin{array}{l}\text { simulation results of maximum electrical field gives almost identical results } \\
\text { for each electrode configuration except for R6-plane. }\end{array}$ \\
\hline
\end{tabular}

Electrode configuration

Finite Element Method (FEM)

Maximum Electric field

Copyright $@ 2018$ Institute of Advanced Engineering and Science. All rights reserved.

\section{Corresponding Author:}

Hidayat Zainuddin,

High Voltage Engineering Research Laboratory,

Faculty of Electrical Engineering,

Universiti Teknikal Malaysia Melaka, Malaysia.

Email: hidayat@utem.edu.my

\section{INTRODUCTION}

An advance improvement in power sector of nation has given a big chance to empower engineers to conserve the power equipment for reliable operation during their operating life. Till now, it has been seen that one of the main problems in high voltage power equipment is the deterioration of its insulation quality [1-2]. In general, there are three different states of insulation that are commonly used; gas, liquid and solid. For gas insulation system, air is one of the simplest forms of gas used as insulating purposes because it has a unique feature of being universally and immediately available at no cost [3]. Futhermore, air has been recommended as environmentally uncritical insulation media for gas insulated electrical power equipment [45]. The resistivity of air can be considered as infinite under normal conditions when there is no ionization [6]. In advance, the breakdown of air is very importance to design engineers of power transmission lines and power apparatus [4].

The electric breakdown strength of an air-insulated gap between different metal electrodes can be enhanced considerably by an experiment. In the past few decades, a number of research works has been done to improve understanding about the fundamental characteristics of the electrical breakdown. The research results show that electrical breakdown characteristic of small air gap under different applied voltage has its great significance for the design of overhead line, substation equipment and other various air insulated high voltage equipment [1]. So, knowledge on the behavior of air breakdown becomes very important and due to 
this reason, there are needs to investigate the breakdown voltage and electric field properties of air during breakdown processes in various environments.

A technique of determining electric field is needed to fully understand the behavior of air under certain electric field profiles. It is difficult to properly measure the electric field at all locations between two electrodes. For simple electrode geometries, the electric fields can easily be expressed analytically, but for some cases the electric field problem is complex due to the complexity of the designed geometries [7-8]. Therefore, numerical methods are the most significant techniques to used in solving specific problems, usually applicable when involving complex systems where the analytical solution is very complicated or impossible [8]. This technique is being commercially used since it allows the user to avoid expensive and complex trial-and-error laboratory experiments which are often very difficult to carry out [9].

In this paper, an air breakdown voltage test subjected to AC voltage was conducted inside a test rig for various electrode configurations and gap length. In order to determine the maximum electric field, a finite element method (FEM) is used for the computer simulation. FEM is a numerical method that is extensively used to obtain solutions for various engineering and science problems, including those are associated with electric field behaviour [10-11]. Thus, a simulation model of the selected electrode configurations with various gap lengths is developed in the computer software to analyze their electrical field behavior inside a test rig.

\section{RESEARCH METHOD}

\subsection{Experimental Setup}

Figure 1 shows a custom made test rig that was used in this study. This test rig is the courtesy of Indkom Engineering Sdn. Bhd where it was designed with a volume capacity of 205 litres and can withstand up to $70 \mathrm{kV}$ in one minute.

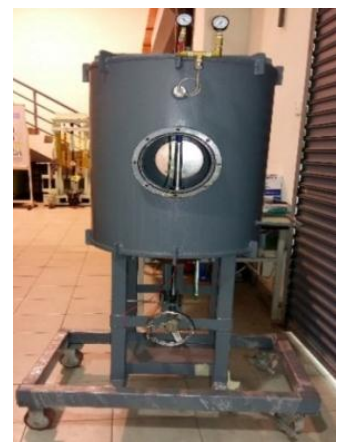

Figure 1. Custom Made Test Rig

To represent various type of electric field, four electrode configurations as shown in Figure 2 are used; plane-plane, R0.5-plane, R6-plane (also known as hemisphere-plane), and R48-plane configurations. The plane electrode has a diameter of $100 \mathrm{~mm}$. Meanwhile, R0.5, R6 and R48 electrodes have a tip radius of $0.5 \mathrm{~mm}, 6 \mathrm{~mm}$ and $48 \mathrm{~mm}$, respectively. All electrodes are made of brass metal.

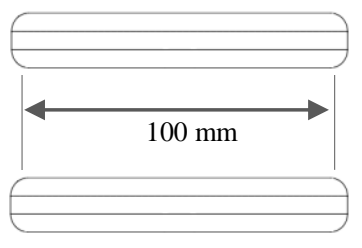

(a) Plane-Plane

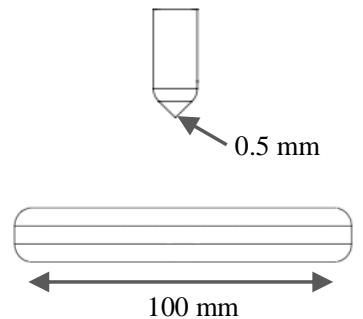

(b) R0.5-Plane

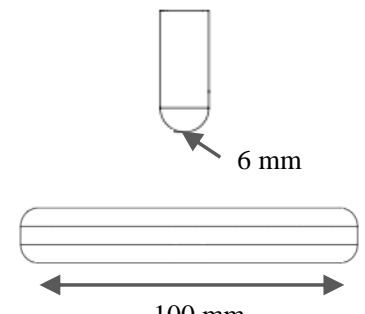

(c) R6-Plane

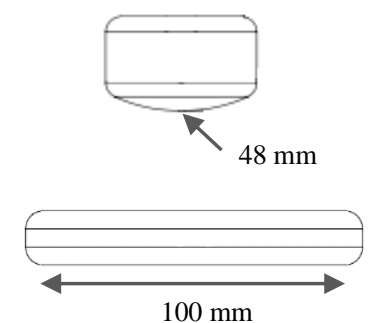

(d) R48-Plane

Figure 2. Electrode Configurations 
In this study, a series of air breakdown voltage test was conducted by using AC voltages (power frequency) and the test procedure of this test is complying with BS EN 60060-1 standard [12]. A minimum of 50 measurements on each experiment was taken for the purpose of statistical analysis. The results of air breakdown obtained from the test measurements are then used in simulation to determine the associated electric field for each electrode configurations.

\subsection{Simulation of Maximum Electric Field using COMSOL Multiphysics Software}

COMSOL Multiphysics 5.2a version software is used to model various electrode configurations inside the test rig for electric field simulation purposes. Each electrode configuration has its own individual model for further analysis its electric field behavior with their respective air breakdown results. In general, there are three stages involved in order to solve a particular problem, which are the pre-processing stage, solving stage, and post-processing stage. All the process involved in each stage is summarized as in Figure 3.
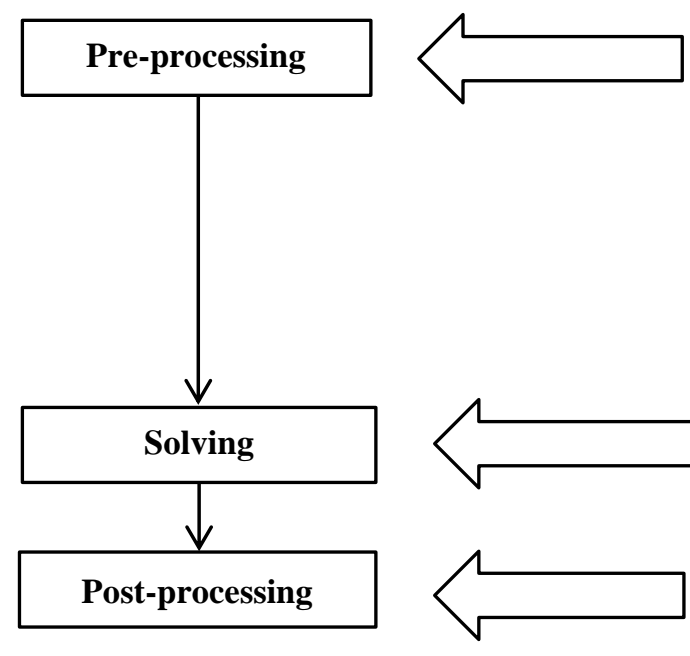

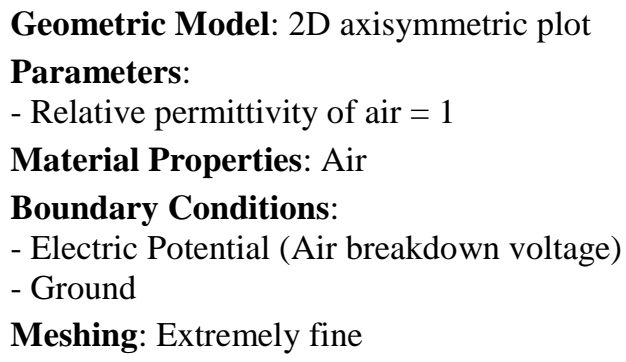

Geometric Model: 2D axisymmetric plot Parameters:

- Relative permittivity of air $=1$

Material Properties: Air

Boundary Conditions:

- Electric Potential (Air breakdown voltage)

- Ground

Meshing: Extremely fine

AC/DC Module - Electrostatic

Execution Mode: Study- Stationary

Results: Electric Potential

Line Plot (1D)

Surface Plot (2D)

Figure 3. FEM Procedures in COMSOL Multiphysics Software

\section{RESULTS AND ANALYSIS}

Air breakdown test subjected to AC voltage was conducted in a test rig with a pressure of $1 \mathrm{~atm}$. During the test, it was recorded that the relative humidity and temperature inside the test rig are varied between $44 \%$ to $78 \%$ and $28.3^{\circ} \mathrm{C}$ to $30.1^{\circ} \mathrm{C}$, respectively. In order to ensure all the tests meet BS EN 60060-1 standard [12], it is fairly important to consider correction factors for each test condition. Therefore, all breakdown voltage results presented in this paper are after considering the correction factor.

Figure 4 shows the experimental results of air breakdown for four different electrode configurations. In this study, $\mathrm{U}_{50}$ is refers to the mean values of 50 breakdown voltage data. It can be seen that the $\mathrm{U}_{50}$ value of air increases with increasing gap length for each electrode configurations. For each gap length, the lowest $\mathrm{U}_{50}$ result is observed for R0.5-plane, while the highest is plane-plane. It is also found that the pattern of $\mathrm{U}_{50}$ values curves for R0.5-plane is close to R6-plane, while R48-plane is close to plane-plane. This is due to the effect of the high voltage electrodes tip radius. As can be seen in Figure 4, the difference in the values of $U_{50}$ between R0.5-plane and R6-plane are decreased as the gap length increases. However, the difference of $U_{50}$ values between R48-plane and plane-plane seems to be increased as the gap length increases especially at above $30 \mathrm{~mm}$. 


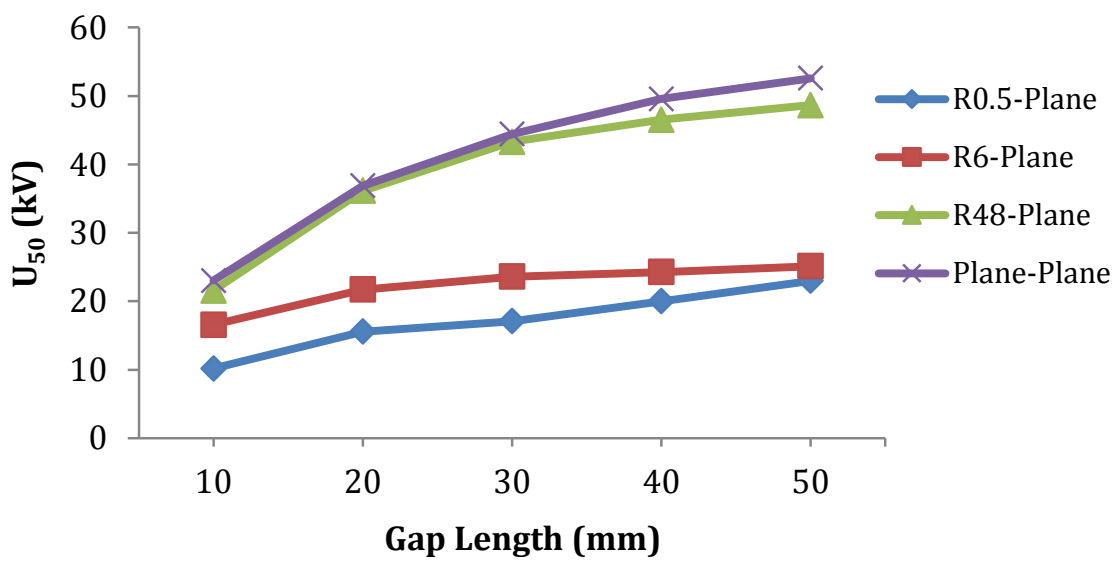

Figure 4. Experimental Results of U50 for Air Breakdown as a Function of Gap Length

\subsection{Maximum Electric Field Simulation}

Based on the $U_{50}$ values determined from the experiment, maximum electric field $\left(E_{\max }\right)$ for each electrode configurations are modelled and simulated in COMSOL Multiphysics software. From the simulation results, the location of $\mathrm{E}_{\max }$ can be determined at a very high stress region in the electrode system.

Figure 5 to Figure 8 show the electric field surface plot (left side) and electric field curve plot (right side) for each electrode configurations at $10 \mathrm{~mm}$ gap length. It is noted that the surface plot displays the location of $E_{\max }$, while the curve plot displays the electric field along the given length. The color table range shows how the electric field varies between the electrode configurations. Dark red color represents the highest (maximum) electric field while dark blue color is associated with the lowest electric field.
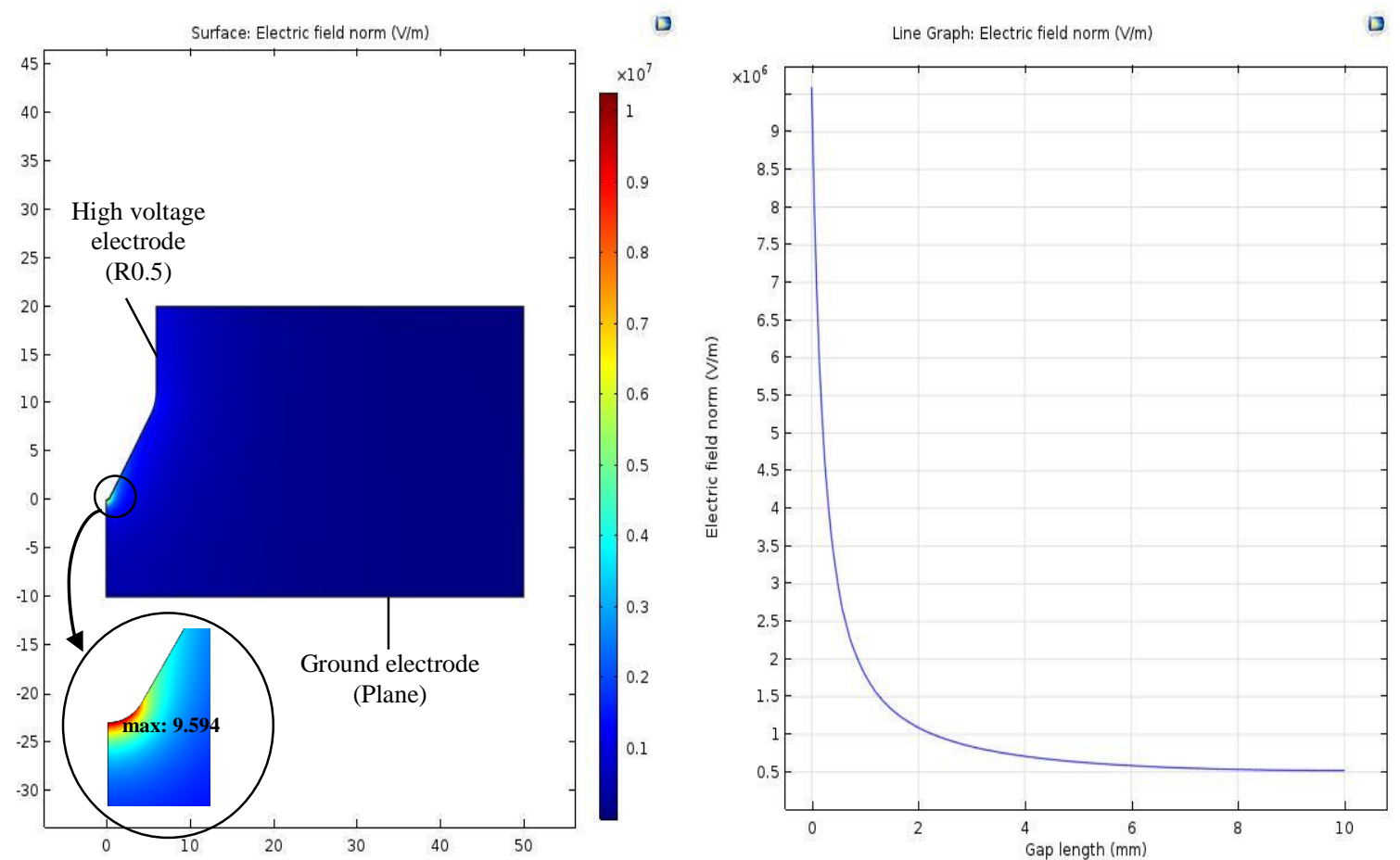

Figure 5. Electric Fields between R0.5-Plane Electrode Configurations (10 mm) 

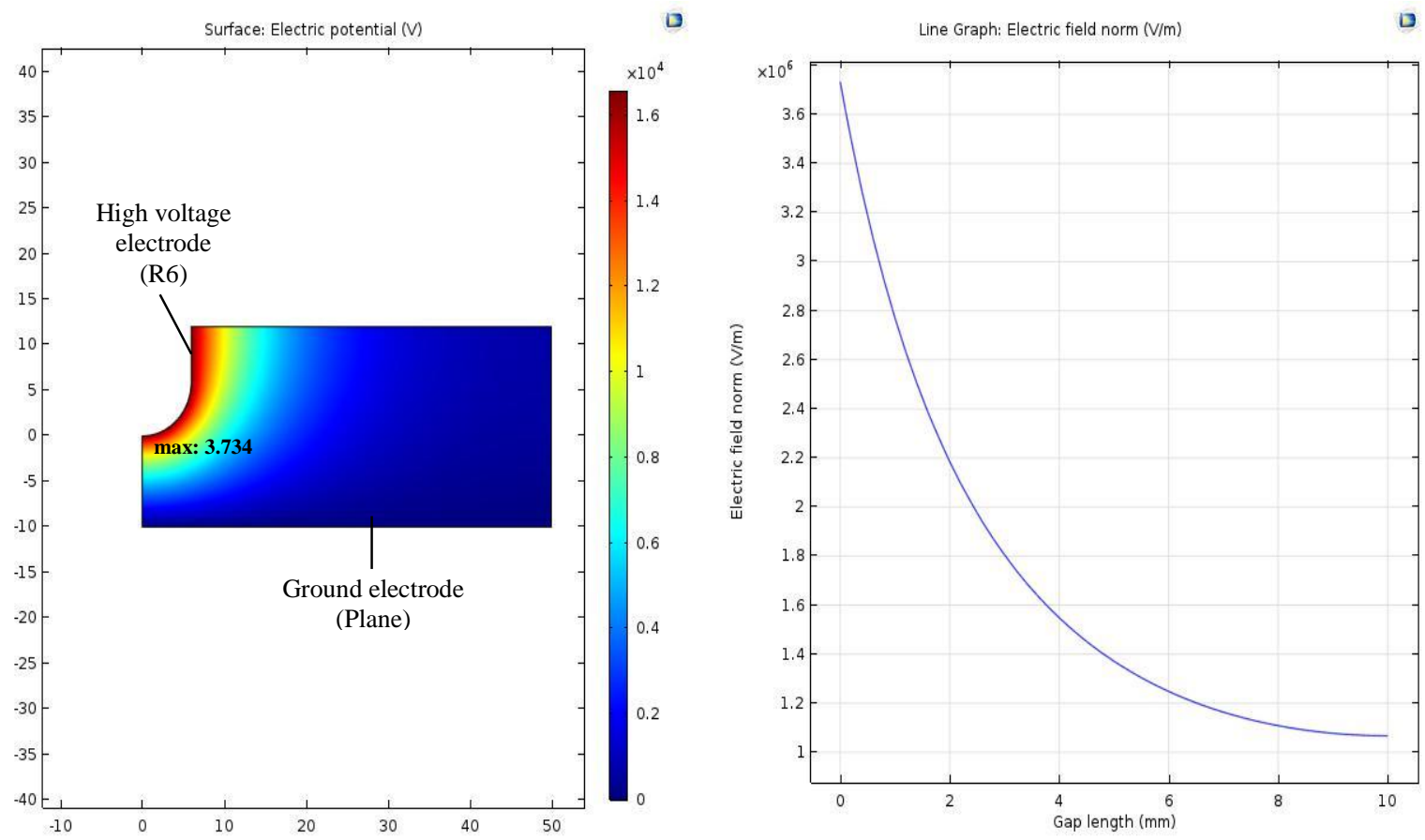

Figure 6. Electric Fields between R6-Plane Electrode Configurations (10 mm)
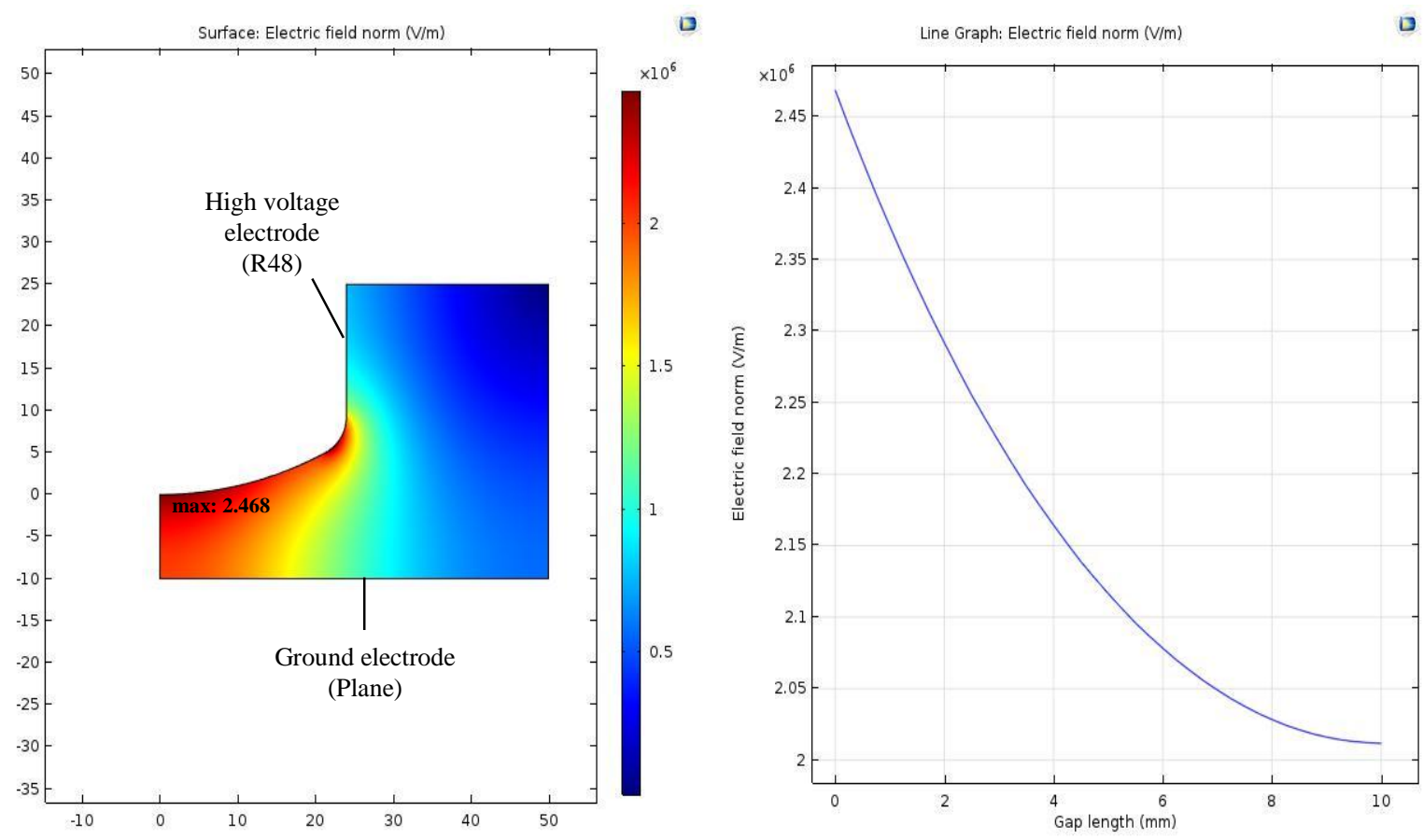

Figure 7. Electric Fields between R48-Plane Electrode Configurations (10 mm) 

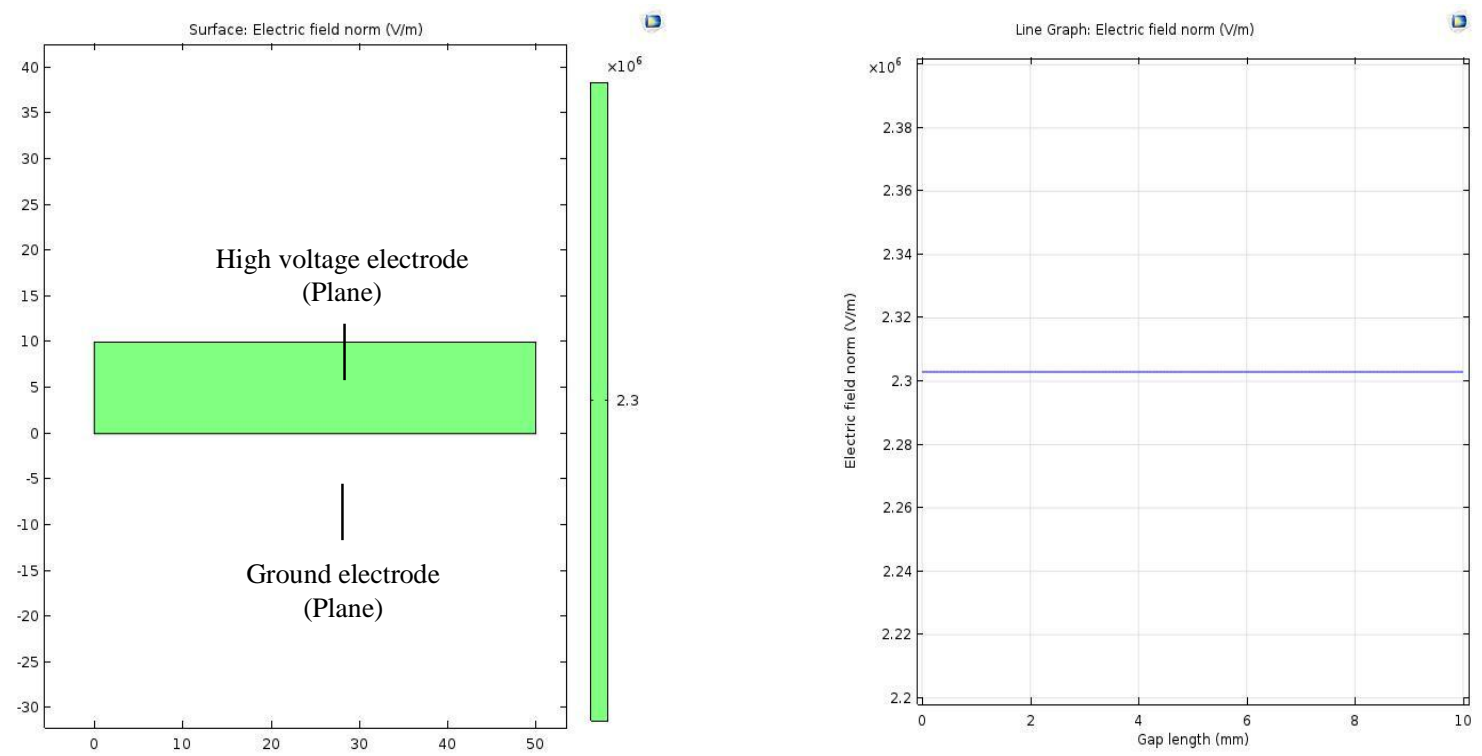

Figure 8. Electric Fields between Plane-Plane Electrode Configurations (10 mm)

Reviewing Figure 5 to Figure 7, the Emax occurs at the tip of the high voltage electrode with dark red color shade. The highest Emax value is observed on R0.5-plane, $9.594 \mathrm{kV} / \mathrm{mm}$. Meanwhile, Emax values for R6-plane and R48-plane are $3.734 \mathrm{kV} / \mathrm{mm}$ and $2.468 \mathrm{kV} / \mathrm{mm}$, respectively. Besides that, it is also observed that the electric field curve decreases exponentially along the $10 \mathrm{~mm}$ gap length for R0.5-plane, R6plane and R48-plane. However, the electric field curve for R0.5-plane is seems to be decreased more sharply compared to the other two configurations. On the other hand, the Emax value for plane-plane is 2.303 $\mathrm{kV} / \mathrm{mm}$. It is observed that the electric field is constant along the gap length, differ from other electrode configurations since there is no curve or sharp edge presence on the plane electrode.

For more in-depth analysis on the electric field behavior, simulation of Emax value of each electrode configuration is conducted for other gap lengths (i. e. $20 \mathrm{~mm}, 30 \mathrm{~mm}, 40 \mathrm{~mm}$, and $50 \mathrm{~mm}$ ). From the simulation results, it is noticed that the electric field plot for all electrode configurations are almost identical as presented in Figure 5 to Figure 8, except for their Emax values.

As depicted in Figure 9, it is clearly shown that the highest Emax are obtained when R0.5-plane is used compared to R6-plane, R48-plane and plane-plane configurations, although with lower U50 values. This is due to the fact that the $\mathrm{R} 0.5$ electrode has a very sharp tip with $0.5 \mathrm{~mm}$ radius. As the tip radius of high voltage electrode increases, Emax values are decreased. Moreover, as a function of gap length, the Emax values for R6-plane, R48-plane and plane-plane configurations decrease as the gap length between the electrodes are increased. In contrast, Emax values for R0.5-plane increases as the gap length are increased.

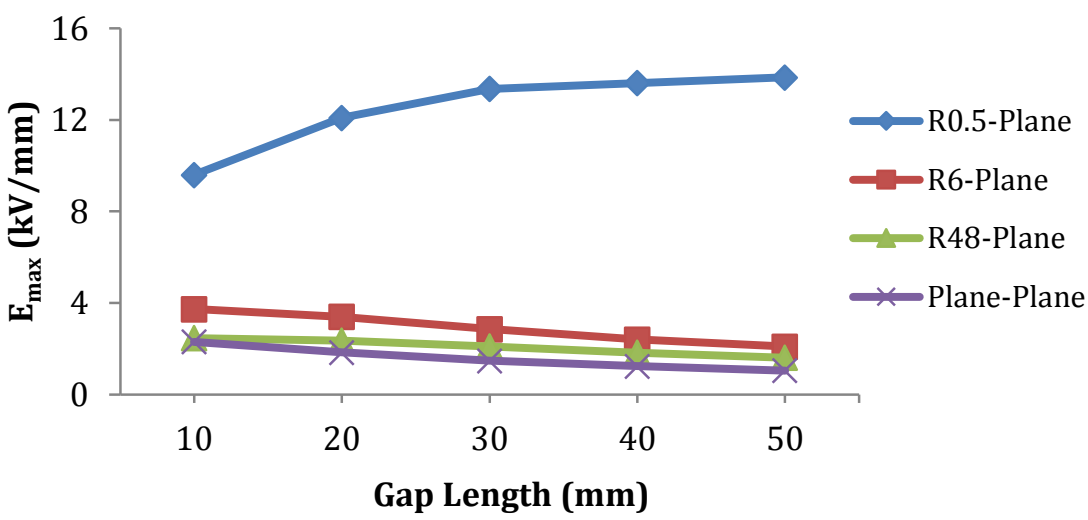

Figure 9. Simulation Results of $\mathrm{E}_{\max }$ as a Function of Gap Length 
Moreover, the relationship between the air breakdown voltage $\left(\mathrm{U}_{50}\right)$ and the maximum electric field $\left(E_{\max }\right)$ can be further analyzed by comparing Figure 4 and Figure 9 . It was observed that the uniformity of the electric field between high voltage and ground electrodes affects the breakdown voltage values. The more non-uniform the electric field between the electrodes, the lower the breakdown voltage values obtained and vice versa. It is worthwhile noting that the uniformity of the electric field increases with the electrode radius. In this study, the most uniform electric field is obtained when the plane-plane electrodes are used, whilst the most non-uniform electric field is observed when R0.5-plane electrodes are used.

To aid understanding, consider a gap length of $10 \mathrm{~mm}$ whereby the breakdown voltage level for plane-plane configuration is approximately $23 \mathrm{kV}$, whilst it is about $10 \mathrm{kV}$ when R0.5-plane configuration is used (refer Figure 4). However, the $E_{\max }$ value for plane-plane configuration is about $2.3 \mathrm{kV} / \mathrm{mm}$, whilst the $\mathrm{E}_{\max }$ for R0.5-plane configuration is $76 \%$ higher, i.e. $9.6 \mathrm{kV} / \mathrm{mm}$ (refer Figure 9). If one considers a voltage level of $10 \mathrm{kV}$ in the case of plane-plane configuration, the $\mathrm{E}_{\max }$ value produced will be too low (i.e. 1.0 $\mathrm{kV} / \mathrm{mm}$ ), thus it is insufficient to initiate a pre-breakdown streamer. Nevertheless, for the case of R0.5-plane configuration, at the same voltage level of $10 \mathrm{kV}$, the $E_{\max }$ which exists at the sharp tip of the electrode introduces a very high stress region that sufficient to initiate a pre-breakdown streamer, thus lead to a breakdown event. Therefore, this explains the reason electrodes with a small tip radius has a lower breakdown voltage level compared to electrodes with a larger tip radius.

\subsection{Comparison between Simulation and Analytical Results of $\mathbf{E}_{\max }$}

This section discusses the comparison between simulation and analytical results of $\mathrm{E}_{\max }$. The simulation results were determined using COMSOL Multiphysics software, as presented in section 3.2. Meanwhile, the analytical results are calculated using the proposed equations according to the types of electrode configurations as shown in Table 1. For R0.5-plane configuration, the R0.5 electrode has a point tips with $0.5 \mathrm{~mm}$ radius. According to Howard [15], the $\mathrm{E}_{\max }$ value at the point of either point-plane or pointsphere configuration can be assumed to be the same as the formula in equation (1) which was derived based on hyperboloidal approximation. In the case of R6-plane configuration, the R6 electrode has a hemisphericalshaped at the end of its tip. Due to this reason, R6-plane can be categorized as hemisphere-plane. The $\mathrm{E}_{\max }$ value for this configuration is calculated using equation (2). Although this equation is derived upon the field between a sphere-plane configuration [16], but it is believed that the electric field distribution at the sphere electrode is dominated by the hemisphere that faces the plane electrode. As a proof, a finite element simulation was conducted to determine the suitability in applying the $\mathrm{E}_{\max }$ equation of sphere-plane to the hemisphere-plane. As a result, both configurations gave almost similar $\mathrm{E}_{\max }$ values (i. e. the $\mathrm{E}_{\max }$ value of hemisphere-plane is greater than the $\mathrm{E}_{\max }$ value of sphere-plane with error less than $3.2 \%$ ). For R48-plane configuration, the $\mathrm{E}_{\max }$ value is estimated using the same equation used for R6-plane since their electric field behavior aforementioned is in agreement to each other (compare the electric field curve plot between Figure 6 and Figure 7). Lastly, for plane-plane configuration, the $E_{\max }$ value is calculated using equation (3) since the electric field exists at any point between this electrodes gap are equal to the average electric field, $\mathrm{E}_{\text {mean. }}$.

Table 1. Formula for $\mathrm{E}_{\max }$ Corresponding to Each Electrode Configurations

\begin{tabular}{lll}
\hline Electrode Configurations & Formula for $\mathrm{E}_{\max }$ & Ref \\
\hline (a) $_{\text {(a) }}$ & $E_{\max }=\frac{2 V}{r \ln \left(\frac{4 d}{r}\right)}$
\end{tabular}

Where: $V=\mathrm{U}_{50}$ value, $r=$ tip radius, $d=$ gap length

$$
E_{\max }=k \frac{V}{d} \frac{r+d}{r}
$$

(b)

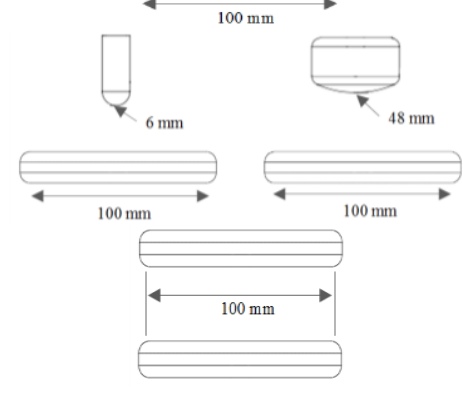

Where: $V=\mathrm{U}_{50}$ value, $r=$ tip radius, $d=$ gap length, $k=0.9$

$$
E_{\text {max }}=E_{\text {mean }}=\frac{V}{d}
$$

Where: $V=\mathrm{U}_{50}$ value, $d=$ gap length 
Table 2 shows the $\mathrm{E}_{\max }$ values for both simulation and analytical (calculated) results under various electrode configurations and gap length. For R0.5-plane configuration, both calculated and simulation results of $E_{\max }$ values are close to each other especially at $10 \mathrm{~mm}, 20 \mathrm{~mm}$ and $40 \mathrm{~mm}$ with error less than $5 \%$. Meanwhile, for R6-plane configuration, it can be seen that the difference of $\mathrm{E}_{\max }$ values between calculated and simulation results are increased as the gap length increases where the errors are varied from $6.5 \%$ to $100.9 \%$. It is believed that this is due to the fixed coefficient $k$ value in equation (2) which gives the significant effects to the results of $\mathrm{E}_{\max }$ as the gap length is varied. On the other hand, for R48-plane configuration, it is observed that the error between calculated and simulation results of $\mathrm{E}_{\max }$ vary from $0.3 \%$ to $10.7 \%$. Lastly, for plane-plane configuration, it can be seen that the $\mathrm{E}_{\max }$ results obtain from both calculation and simulation are similar for all gap length.

Table 2. Comparison between Analytical and Simulation Results of $E_{\max }(\mathrm{kV} / \mathrm{mm})$

\begin{tabular}{|c|c|c|c|c|c|c|c|c|c|c|c|c|}
\hline \multirow[b]{2}{*}{$\begin{array}{l}\text { Gap } \\
(\mathrm{mm})\end{array}$} & \multicolumn{3}{|c|}{ R0.5-Plane } & \multicolumn{3}{|c|}{ R6-Plane } & \multicolumn{3}{|c|}{ R48-Plane } & \multicolumn{3}{|c|}{ Plane-Plane } \\
\hline & (a) & COMSOL & $\begin{array}{c}\text { Error } \\
(\%)\end{array}$ & (b) & COMSOL & $\begin{array}{c}\text { Error } \\
(\%)\end{array}$ & (b) & COMSOL & $\begin{array}{c}\text { Error } \\
(\%)\end{array}$ & (c) & COMSOL & $\begin{array}{c}\text { Error } \\
(\%)\end{array}$ \\
\hline 10 & 9.295 & 9.594 & 3.1 & 3.978 & 3.734 & 6.5 & 2.346 & 2.468 & 4.9 & 2.303 & 2.303 & 0 \\
\hline 30 & 12.482 & 13.354 & 6.5 & 4.248 & 2.861 & 48.5 & 2.111 & 2.104 & 0.3 & 1.480 & 1.480 & 0 \\
\hline 40 & 13.867 & 13.609 & 1.9 & 4.186 & 2.402 & 74.3 & 1.919 & 1.830 & 4.9 & 1.239 & 1.239 & 0 \\
\hline 50 & 15.359 & 13.858 & 10.8 & 4.219 & 2.100 & 100.9 & 1.788 & 1.615 & 10.7 & 1.052 & 1.052 & 0 \\
\hline
\end{tabular}

* (a), (b), and (c) are calculated according to formula in equation (1), (2) and (3), respectively.

\section{CONCLUSION}

Overall, AC breakdown test subjected to air were conducted to obtain U50 data under various electrode configurations and gap lengths. There are four different electrode configurations were used; planeplane, R0.5-plane, R6-plane and R48-plane. Meanwhile, the gap length is varied between $10 \mathrm{~mm}$ to $50 \mathrm{~mm}$ in $10 \mathrm{~mm}$ interval. After conducting the air breakdown test, the U50 values are then used to determine the Emax using a 2D axisymmetric model in COMSOL Multiphysics software. The location of the maximum electric field was determined for each electrode configurations, and electric field curves between the high voltage and ground electrodes are also plotted and examined. It was found that although the air breakdown results in R0.5-plane gaps are lower than the other electrode configurations, the Emax values are the highest among all the electrode configurations. The analytical and simulation results of Emax for each electrode configurations are almost similar to each other except for R6-plane.

\section{ACKNOWLEDGEMENTS}

The authors wish to thank Malaysian Ministry of Higher Education (MOHE) and Universiti Teknikal Malaysia Melaka (UTeM) for funding this study under the research grants; FRGS/1/2016/TK04/FKE-CERIA/F00304. An appreciation also gives to Indkom Engineering Sdn. Bhd. for providing certain research materials throughout this study.

\section{REFERENCES}

[1] P. B. Sankar, "Measurement of Air Breakdown Voltage and Electric Field using Standard Sphere Gap Method," Master Thesis, 2011.

[2] S. Karmakar, “An Experimental Study of Air Breakdown Voltage and its Effects on Solid Insulation,” J. Electrical Systems, pp. 209-217, 2012.

[3] M. S. Kamarudin et al., "A Survey on the Potential of CF3I as an Alternative for SF6 in High Voltage Applications, " in 45th International Universities Power Engineering Conference (UPEC 2010), pp. 1-5, 2010.

[4] M. S. Naidu and V. Kamaraju, "High Voltage Engineering", 4th ed., Tata McGraw-Hill, 2009.

[5] E. Onal, "Breakdown Characteristics of Gases in Non-Uniform Fields," J. Electr. Electron. Eng., vol. 4, no. 2, pp. 1177-1182, 2004.

[6] G. R. Jones, M. A. Laughton, and M. G. Say, "Electrical Engineer's Reference Book", 15th ed., ButterwortHeinemann Ltd., 1993.

[7] A Kara, Ö. Kalenderli, and K. Mardikyan, "Effect of Dielectric Barriers to the Electric Field of Rod-Plane Air Gap," Eighth COMSOL Conf., 2006.

[8] F. Miron, M. Purcar, and C. Munteanu, "Numerical Computation of the Electromagnetic Field inside a High Voltage Substation," Acta Electrotehnica, vol. 56, no. 4, pp. 175-178, 2015.

[9] M. S. Kamarudin, "Experimental Investigation of CF3I-CO2 Gas Mixtures on the Breakdown Characteristics in Uniform and Non-Uniform Field Configurations," PhD Thesis, 2013. 
[10] S. K. Kanikella, "Electric Field and Thermal Properties of Dry Cable Using FEM", TELKOMNIKA Indonesian Journal of Electrical Engineering, vol. 11, no. 5, pp. 2271-2276, 2013.

[11] K. Rajagopala, K. P. Vittal, and H. Lunavath, "Computation of Electric Field and Thermal Properties of 3-Phase Cable", TELKOMNIKA Indonesian Journal of Electrical Engineering, vol. 10, no. 2, pp. 265-274, 2012.

[12] European Committe for Electrotechnical Standardization, "BS EN 60060-1: 2010 BSI Standards Publication Highvoltage Test Techniques Part 1: General Definitions and Test Requirements," 2010.

[13] M. S. Kamarudin et al., "Simulation of Electric Field Properties for Air Breakdown using COMSOL Multiphysics," in 4th IET International Conference on Clean Energy and Technology (CEAT 2016), 2016.

[14] M. S. Kamarudin et al., "Pressurized CF3I-CO2 Gas Mixture under Lightning Impulse and its Solid By-Products", International Journal of Electrical and Computer Engineering (IJECE), vol. 7, no. 6, pp. 3088-3094, 2017.

[15] P. R. Howard, "Process Contributing to the Electronegative Gases in Uniform and Non-Uniform Electric Fields," Proceedings of the IEE - Part A: Power Engineering, vol. 104, no. 14, pp. 139-142, 1957.

[16] A. Bouwers and P. G. Cath, "The Maximum Electric Field Strength for Several Simple Electrode Configurations", Philips Technical Review, vol. 6, no. 9, pp. 270-278, 1941. 


\section{BIOGRAPHIES OF AUTHORS}
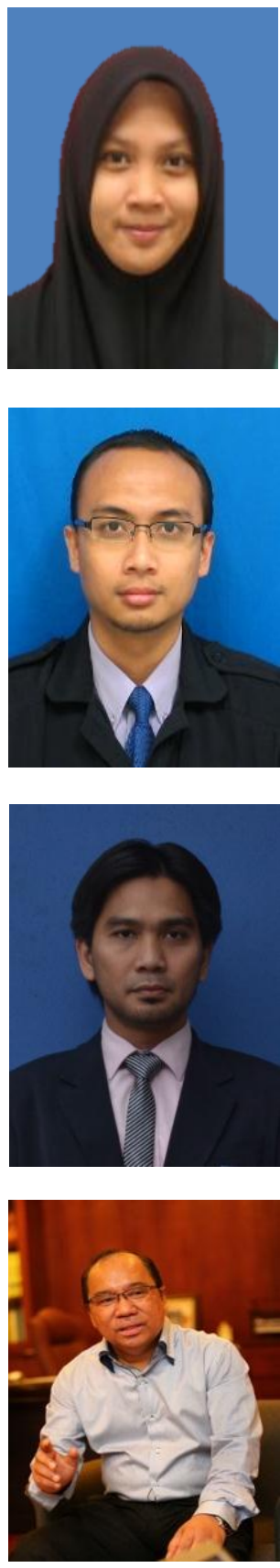

Hidayat Zainuddin received his Bachelor's degree in Electrical Engineering from Universiti Teknologi Malaysia in 2003. He then obtained his Master of Science degree in Electrical Power Engineering with Business from University of Strathclyde, Glasgow, in 2005. He received his Ph.D degree from University of Southampton in 2013. He has served as an academic staff at Universiti Teknikal Malaysia Melaka (UTeM) since 2003 and he is currently an Associate Professor and Deputy Dean (Student Development) in the Faculty of Electrical Engineering, UTeM. He is also the Head of the High Voltage Engineering Research Laboratory (HVER Lab), UTeM. He was the Manager of Centre of Excellence for Robotics and Industrial Automation (CeRIA) at UTeM from 2014 to 2016. His research interests include green technology in high voltage system, high voltage equipment and insulation condition monitoring, failure analysis, and power system protection coordination.

Muhammad Saufi Kamarudin received his PhD Degree in High Voltage Engineering from Cardiff University, UK in 2014. He received his M.Sc. in Electrical Power Engineering and Bachelor of degree in Electrical Engineering (Electrical Power Engineering) from Universiti Teknologi Malaysia in 2003 and 2005. Currently, he is a Senior Lecturer in the Faculty of Electrical and Electronic Engineering, at Universiti Tun Hussien Onn (UTHM). He is a Professional Engineer (Ir.) registered with the board of Engineers Malaysia (BEM). He is also a corporate member of Institution of engineers Malaysia (IEM).His research interest include gas discharge, high voltage surge arresters as well as dielectric, and electrical insulation system.

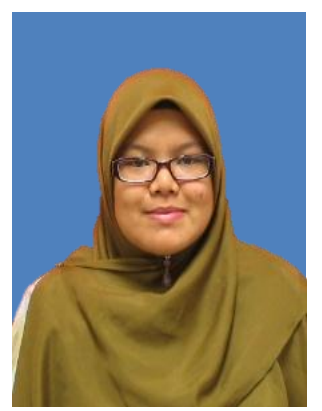

Jamaludin Mohd Wari is a Managing Director of Indkom Engineering Sdn Bhd, a medium voltage switchgear company base in Shah Alam, Selangor. He is a manager, designer and engineer with more than 25 years of experience in electrical power industry. His career path began in 1984 as an Engineer; became Manager in 1989 and later on in 1996 appointed as Managing Director. He had wide exposure and extensive experiences in high voltage distribution and transmission projects with highly engineered systems which require deep understanding of critical business drivers in multiple markets and industries. He led and motivated teams comprised of more than 200 employees and managed P\&L for business divisions exceeding RM100 million revenue.

Ayuamira Zahari received her Bachelor's degree in Electrical Engineering (Control, Instrumentation and Automation) from Universiti Teknikal Malaysian Melaka (UTeM) in 2014. She is currently pursuing her MSc in Electrical Engineering at UTeM. Her research focus mainly on high voltage gas insulation. 